\title{
Geoparque como forma de gestão territorial interdisciplinar apoiada no geoturismo: caso do Projeto Geoparque Seridó
}

\section{Geopark as form of interdisciplinary territorial management supported in geotourism: Seridó Geopark Project case}

Marcos Antonio Leite do Nascimento, Cristiane Soares Cardoso Dantas Gomes, Artemísia dos Santos Soares

\section{RESUMO}

As atividades da proposta Geoparque Seridó iniciaram em 19/04/2010 dentro do Projeto Geoparques do Brasil, criado em 2006 pela CPRM. A parceria entre CPRM e UFRN possibilitou a realização de diferentes ações: (a) Inventário de 25 geossítios com resultados divulgados no site da CPRM e no Livro "Geoparques do Brasil: propostas", lançando em 2012. (b) Projetos na UFRN: (i) Estudo Técnico e Diagnóstico para Criação do Geoparque Seridó, Estado do RN; (ii) Patrimônio Geológico da Região do Seridó (RN, NE do Brasil): inventariação e integração de geossítios para embasar proposta de criação de Geoparque; (iii) Educação Patrimonial em Meio Natural em municípios do Geoparque Seridó (Região Seridó, RN); (iv) Roteiros do Seridó: análise do potencial turístico do Seridó Potiguar e (v) Elaboração do Plano de Desenvolvimento do Turismo do Município de Currais Novos e (c) Elaboração de Dissertação: Geoparque Seridó, RN: valores turísticos e gestão. Nesse período parcerias com SEBRAE/RN e IPHAN/RN permitiram publicar 0 Guia Turístico da Região Seridó (SEBRAE/RN) e o IPHAN/RN tem garantido a preservação do patrimônio arqueológico em geossítios, seja pela atuação no cumprimento da legislação, seja pela execução de obras de socialização/acessibilidade para visitação. Além disso, publicou o livro "Geodiversidade na Arte Rupestre no Seridó Potiguar" com descrição dos elementos da geodiversidade em geossítios. Novas ações estão sendo criadas, são elas: (a) cadastros de novos geossítios; (b) promoção de cursos de educação ambiental e capacitação de guias de turismo e gestores; (c) elaboração de monografia de graduação e dissertação de mestrado; (d) realização de projeto para definição de trilhas geoturísticas; e (e) preparação de material promocional sobre o Geoparque Seridó.

PALAVRAS-CHAVE: Geoparque; Geoturismo; Gestão; Geoparque Seridó. 


\section{ABSTRACT}

The activities of the Seridó Geopark proposal were started in April, $19^{\text {th }}, 2010$ under the context of the Project "Geoparks in Brazil", established in 2006 by CPRM. The partnership between CPRM and UFRN has allowed the development of different actions: (a) Inventory of 25 geosities with results are found on the CPRM website and in the book "Geoparques do Brasil: propostas", published in 2012. (b) Projects developed at UFRN: (I) Technical Study and Diagnose for the Establishing of the Seridó Geopark, State of RN; (ii) Geological Heritage of the Seridó Region (RN, NE Brazil): Inventory and Integration of Geosites to Support Geopark Proposal; (iii) Heritage Education in Natural Environment at the Seridó Geopark municipalities (Seridó Region, $\mathrm{RN}$ ); (iv) Routes of the Seridó: Analysis of the touristic potential of the Potiguar Seridó; (v) Formulation of the Tourism Development Master Plan of Currais Novos and (c) Master's Thesis: The Seridó Geopark, RN: Touristic values and management. In this period partnerships with SEBRAE/RN and IPHAN/RN. published the Guide Book for the Seridó Region (SEBRAE/RN) and IPHAN/RN has ensured the preservation of the archeological heritage in geosites either by acting in compliance with the law, either by running social programs and accessibility constructions. Furthermore, the IPHAN/RN has also published the book "Geodiversidade na Arte Rupestre no Seridó Potiguar" that describes geodiversity elements in geosites. New actions are currently, including: (a) cadastre of new geosites; (b) promotion of environmental education and training courses for tourist guides and managers; (c) writing of Undergraduate Monograph and Master's Thesis; (d) proposal of project on defining geoturistic trails; and (e) preparation of promotional materials of the Seridó Geopark.

KEYWORDS: Geopark, Geotourism, Management, Seridó Geopark.

\section{Introdução}

Preocupados em encontrar alguma forma e/ou recurso para promover a gestão sustentável do patrimônio geológico, os geólogos Guy Martini e Nicolas Zouros, em 1996 durante o XXX Congresso Internacional de Geologia, em Pequim na China, tiveram a ideia de criar uma iniciativa que permitisse o desenvolvimento sustentável por meio da proteção e promoção do patrimônio geológico com a finalidade de desenvolver atividades científicas, educativas e turísticas. Com isso, essa estratégia seria também uma garantia para a conservação desses lugares de interesse geológico.

Em 1997 um importante programa da união europeia de desenvolvimento e cooperação entre zonas rurais (LEADER) possibilitou que quatro territórios europeus (França, Grécia, Alemanha e Espanha) pudessem desenvolver e experimentar o conceito de Geoparque sob a filosofia idealizada pelos geólogos Guy Martini e Nicolas Zouros (MOREIRA, 2011; URQUÍ, 2012). Assim, em 2000 foi criada a Rede Europeia de Geoparques (REG), a primeira do gênero, contando com quatro geoparques: Réserve Géologique de Haute-Provence (França), The Petrified Forest of Lesvos (Grécia), Geopark Gerolstein/Vulkaneifel (Alemanha) e Maestrazgo Cultural Park (Espanha) (ZOUROS, 2004; MC KEEVER; ZOUROS, 2005). 
Desde então, muito tem sido feito para permitir que os geoparques cumpram seu papel de fomentar a educação, conservação e turismo, permitindo assim uma nova forma de gestão territorial interdisciplinar em regiões com patrimônio geológico ímpar, mas associado aos patrimônios biológico e cultural. Esse artigo objetiva apresentar a evolução do conceito de geoparque no Mundo e no Brasil, culminando com as diferentes ações a favor da construção desse novo conceito em terras potiguares, por meio do Projeto Geoparque Seridó.

\section{Geoparque - uma realidade}

A geologia e a paisagem influenciaram profundamente a sociedade, a civilização e a diversidade cultural de nosso planeta. Mas, até poucos anos atrás, não havia o reconhecimento internacional do patrimônio geológico de importância nacional ou regional e não havia especificamente uma convenção internacional sobre o patrimônio geológico. A iniciativa da UNESCO de apoiar a criação de geoparques responde à forte demanda expressa por muitos países por meio de uma rede global no sentido de aumentar 0 valor do patrimônio da Terra, suas paisagens e formações geológicas, que também são testemunhas-chave da história da vida.

Geoparque (ou geopark, em inglês) é uma marca atribuída pela Rede Global de Geoparques sob os auspícios da UNESCO a uma área onde sítios do patrimônio geológico representam parte de um conceito holístico de proteção, educação e desenvolvimento sustentável. Um geoparque deve gerar atividade econômica, notadamente por intermédio do turismo, e envolve um número de sítios geológicos (ou geossítios) de importância científica, raridade ou beleza, incluindo formas de relevo e suas paisagens. Vale salientar que aspectos arqueológicos, ecológicos, históricos ou culturais podem representar também importantes componentes de um geoparque (NASCIMENTO et al., 2008).

Geograficamente, um geoparque representa uma área suficientemente grande, com limites bem definidos para servir ao desenvolvimento econômico local, no entanto um geoparque não é uma unidade de conservação, nem uma nova categoria de área protegida. A ausência de um enquadramento legal de um geoparque é a razão do sucesso dessa iniciativa em nível mundial. deve:

Em suma, um geoparque no conceito da Rede Global de Geoparques

1.Proteger o patrimônio geológico para futuras gerações (geoconservação);

2.Educar e ensinar o grande público sobre temas geológicos e ambientais e prover meios de pesquisa para as geociências;

3.Assegurar o desenvolvimento sustentável por meio do geoturismo, reforçando a identificação da população com sua região, promovendo o respeito ao meio ambiente e estimulando a atividade socioeconômica com a criação de empreendimentos locais, pequenos negócios, indústrias de hospedagem e novos empregos e; 
4.Gerar novas fontes de renda para a população local e a atrair capital privado.

A Rede Global de Geoparques Nacionais, comumente referida como Rede Global de Geoparques (ou Global Geoparks Network - GGN, em inglês), foi criada em 13 de fevereiro de 2004 em reunião realizada na sede da UNESCO, em Paris, da qual participaram os membros do Conselho Científico do Programa Internacional de Geociências - IGCP, representantes da União Geográfica Internacional - IGU e da União Internacional das Ciências Geológicas - IUGS, além de especialistas internacionais sobre a conservação e promoção do patrimônio geológico (URQUí, 2012). A GGN é uma rede internacional não governamental, voluntária e sem fins lucrativos que fornece uma plataforma de cooperação entre os geoparques e reúne órgãos governamentais, organizações não governamentais, cientistas e comunidades de todos os países ao redor do mundo em uma única parceria global, operando de acordo com os regulamentos da UNESCO (EDER; PATZAK, 2004).

Em junho de 2004, durante a I Conferência Internacional de Geoparques realizada na China, a Rede Global de Geoparques era composta por 25 geoparques (17 europeus e 8 chineses). Lembrando que tudo começou no ano 2000 com apenas 4 geoparques na Europa.

Atualmente (portanto apenas 15 anos depois), a rede já possui 111 geoparques em 32 países de diversas partes do mundo, representados por Alemanha $(5+1$ binacional com Polônia); Áustria $(3+1$ binacional com a Eslovênia); Brasil (1); Canadá (2); China (31); Coréia do Sul (1); Croácia (1); Dinamarca (1); Eslováquia (1 binacional com Hungria); Eslovênia (1 + 1 binacional com a Áustria); Espanha (10); Finlândia (1); França (5); Grécia (4); Holanda (1); Hungria (1 + 1 binacional com Eslováquia); Indonésia (1); Irlanda $(2+1$ binacional com a Irlanda do Norte); Irlanda do Norte (1 binacional com a Irlanda); Islândia (1); Itália (9); Japão (7); Malásia (1); Marrocos (1); Noruega (2); Polônia (1 binacional com Alemanha); Portugal (4); Reino Unido (6); República Tcheca (1); Romênia (1); Turquia (1); Uruguai (1) e Vietnam (1). Há 64 geoparques em 23 países da Europa, 42 em 6 países da Ásia, e 4 nas Américas, sendo 1 no Brasil e 1 na África. Mais detalhes em http://www.globalgeopark.org/ e na Figura 1 (página seguinte).

Com o principal objetivo de estimular a troca de experiências entre países, aproveitando, ao mesmo tempo, os instrumentos financeiros disponibilizados, a Rede Global de Geoparques organiza, a cada dois anos, conferências entre os seus membros e apresentação de novos geoparques aspirantes. Já foram realizadas seis conferências, sendo a $1^{a}$ em Pequim, China (2004); 2a em Belfast, Irlanda do Norte (2006); 3a em Osnabruck,

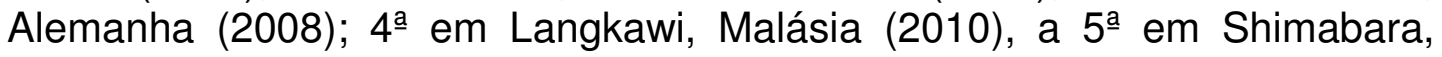
Japão (2012) e a 6⿳a em Saint John New Brunsick, Canadá (2014). Está programada para ocorrer em 2016, em Devon, Reino Unido, a 7ª conferência internacional de geoparques, junto ao English Riviera Global Geopark. 


\section{Distribution of GGN Members}

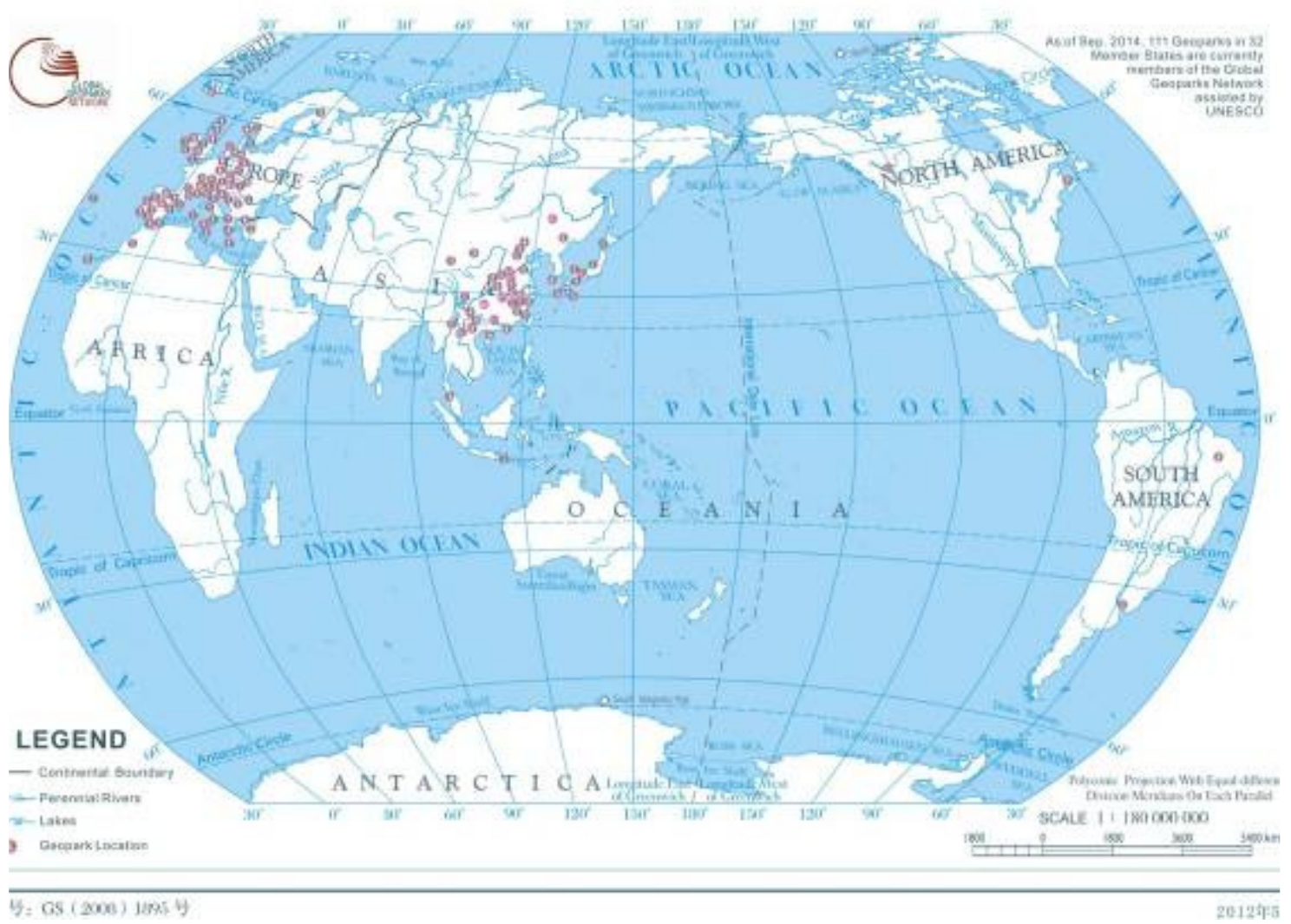

Figura 1: Mapa com distribuição dos cento e onze geoparques membros da Rede Global de Geoparques. Fonte: Compilado de http://www.globalgeopark.org/.

Figure 1: Map with distribution of one hundred and eleven members of the Global Geoparks Network. Source: Compiled from http://www.globalgeopark.org/

O conceito de geoparque vem se ampliando e se espalhando rapidamente por diversas partes do mundo depois da criação da Rede Global de Geoparques sob os auspícios da UNESCO. Para candidatar-se à rede o aspirante a geoparque deve submeter documento ou dossiê de candidatura (application dossier) à Divisão de Ciências Ecológicas e da Terra (Division of Ecological and Earth Sciences) da UNESCO (MOREIRA, 2011). Esse dossiê deve seguir diretrizes definidas pela Rede Global de Geoparques e é submetido a uma avaliação que inclui uma visita in loco de especialistas ligados à rede.

Vale destacar que a criação de um geoparque implica na formação de uma equipe interdisciplinar bem suportada pelos organismos que, de fato, podem assegurar uma gestão efetiva do território. O apoio político ao nível do município é absolutamente essencial, não só porque é dele que advêm inicialmente os recursos para colocar em marcha um projeto deste tipo (embora possa e deva ter outras fontes complementares, públicas ou privadas) como é por meio do município que se conseguem articular as diversas políticas de desenvolvimento local.

A criação de um Geoparque em uma determinada região pode se revelar como um agente transformador da realidade das comunidades que 0 
compõe. Para o Estado um Geoparque pode representar uma alternativa adequada para promover a conservação em consonância com atividades econômicas. Para as Empresas da Iniciativa Privada que apóiam o Geoparque o retorno é imediato, pois, propicia maior visibilidade e promoção. A Empresa se beneficia de um maior reconhecimento perante a sociedade com medidas compensatórias mais eficazes e visíveis. E para a População um Geoparque pode representar desenvolvimento socioeconômico local, por meio do geoturismo, do comércio, atração do capital privado além do desenvolvimento científico/educativo inerente a função do Geoparque.

Lembrando que Geoparque NÃO é (exclusivamente) GEOLÓGICO, nem é um Parque no sentido usual dessa palavra. Geoparque é um conceito holístico e interdisciplinar, que inclui:

- Um projeto de desenvolvimento regional;

- Atividades turístico-culturais-educacionais apresentadas ao público em linguagem adequada;

- Atividades relativas às belezas naturais e à cultura;

- A continuidade de todas as atividades normais da economia regional;

- De maneira a permitir o aproveitamento e fruição atuais, promover a fixação da população local e estimular o desenvolvimento social, econômico e cultural; e

- Tudo isso com uma visão conservacionista, de desenvolvimento sustentável, ou seja, sem prejudicar seu aproveitamento e fruição pelas gerações futuras.

\section{Geoparque Araripe - o único no Brasil}

Até agora, o Brasil tem somente um geoparque integrado a Rede Global de Geoparques, o Geoparque Araripe (oficializado em setembro de 2006), então o primeiro do Hemisfério Sul e, até 2012 o único geoparque latino-americano.

O Geoparque Araripe está localizado no Sul do Estado do Ceará, Brasil, na região da bacia sedimentar do Araripe. O território do Geoparque compreende aproximadamente $3.441 \mathrm{Km}^{2}$ da área do Ceará, limitando-se com os estados de Pernambuco e Paraíba, e compreendendo os municípios de Crato, Juazeiro do Norte, Barbalha, Missão Velha, Nova Olinda e Santana do Cariri (Figura 2). O Geoparque Araripe é uma iniciativa do Governo do Estado do Ceará, representado em sua criação pela Secretaria de Estado da Ciência, Tecnologia e Educação Superior, e coordenado pela Universidade Regional do Cariri - URCA.

O primeiro Geoparque nacional foi criado pela relevância geológica e paleontológica de seus geossítios que são destinados a visitação turística e a educação ambiental. 


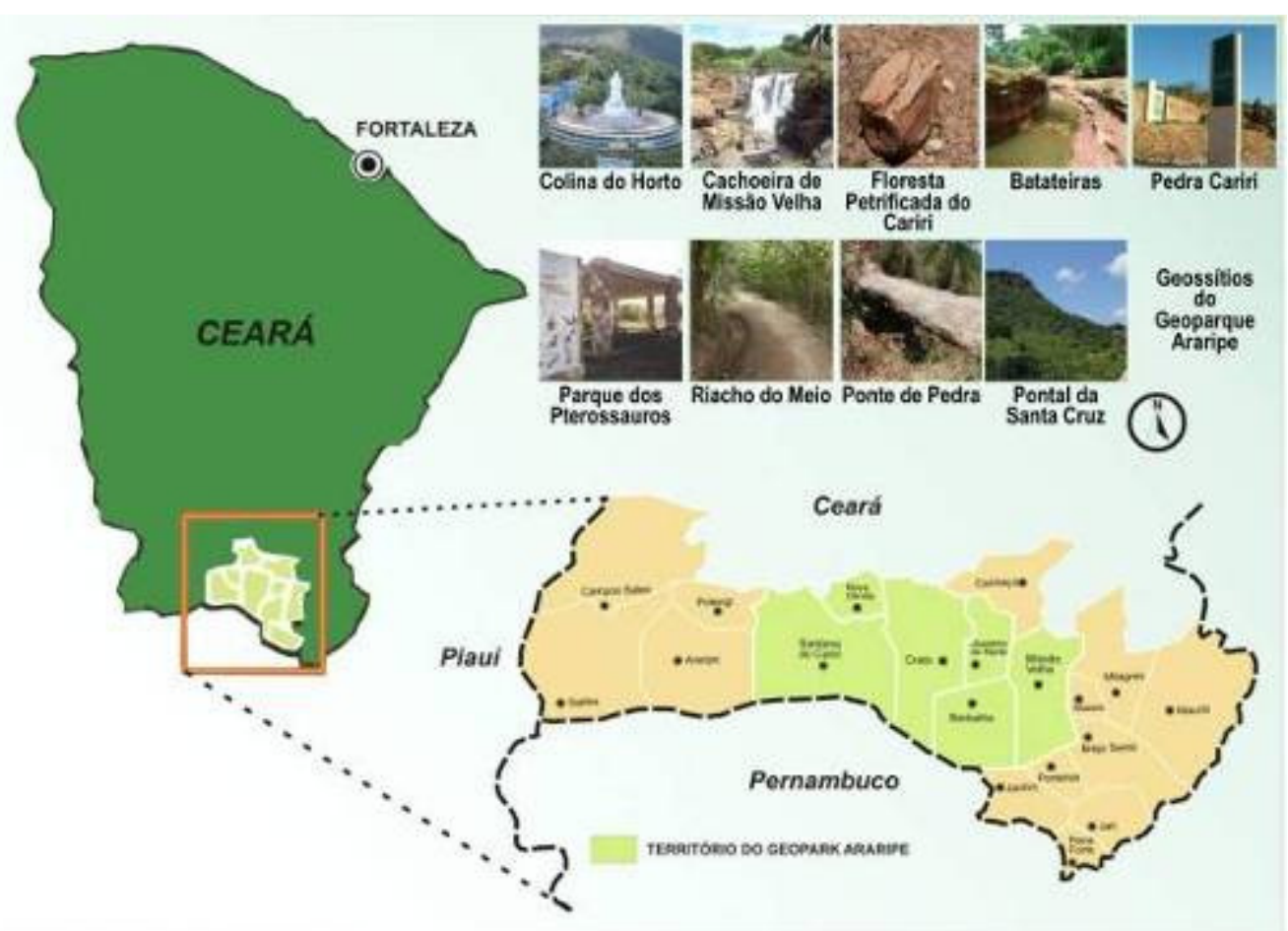

Figura 2: Localização dos municípios que compõem o Geoparque Araripe, no Estado do Ceará, com a identificação dos nove geossítios trabalhados do ponto de vista da conservação, educação e turismo.

Figure 2: Location of the municipalities that formed the Araripe Geopark, State of Ceará, with the identification of the nine geosites worked from the point of view of conservation, education and tourism.

Atualmente o Geoparque Araripe é formado por nove geossítios (Colina do Horto, Cachoeira de Missão Velha, Floresta Petrificada do Cariri, Batateiras, Pedra Cariri, Parque dos Pterossauros, Riacho do Meio, Ponte de Pedra, Pontal da Santa Cruz), definidos pela relevância geológica e paleontológica e considerados os locais mais representativos de seus estratos geológicos e de suas formações fossilíferas (Figura 2) (BRITO; PERINOTTO, 2012).

O novo espaço atrai interesse para o turismo científico e geológico (geoturismo), gerando renda para o setor hoteleiro da região e para a população local, sendo também uma forma importante de divulgar e conservar os recursos naturais lá existentes. Mais detalhes acessar o site http://geoparkararipe.org.br/.

\section{O Projeto Geoparques da CPRM}

O Projeto Geoparques, criado pelo Serviço Geológico do Brasil CPRM em 2006 tem um importante papel indutor na criação de geoparques no Brasil, uma vez que esse projeto possui como premissa básica a identificação, levantamento, descrição, diagnóstico e ampla divulgação de áreas com potencial para futuros geoparques no território nacional, bem como inventário e quantificação de geossítios. 
Para esse projeto utiliza-se a experiência do corpo técnico da empresa, além do aporte de estudos e propostas da comunidade geocientífica. Em alguns casos, essa atividade indutora é feita em parceria ou com o apoio de entidades governamentais ou privadas, em especial universidades que tenham interesses comuns, em consonância com as comunidades locais. A ação catalisadora desenvolvida pela CPRM representa, entretanto, somente o passo inicial para o futuro geoparque. A posterior criação de uma estrutura de gestão do geoparque, contando com pessoal técnico especializado e outras iniciativas complementares, é essencial e deverá ser proposta por autoridades públicas, comunidades locais e interesses privados agindo em conjunto.

O Brasil, com sua rica geodiversidade, contendo testemunhos de praticamente todas as eras geológicas (Figura 3) e aliada à sua imensa extensão territorial, possui grande potencial para a proposição de geoparques. Registros importantes dessa história, alguns de caráter único, representam parte do patrimônio natural da nação. A existência de registros do patrimônio geológico é condição importante, mas não é suficiente para a proposição de um geoparque, na concepção da Rede Global de Geoparques, sendo necessário unir-se a sítios não geológicos de importância ecológica, arqueológica, histórica ou cultural. Em um geoparque ainda é importante envolver uma iniciativa inovadora destinada a proteger e gerir o patrimônio geológico de forma sustentável, maximizando o geoturismo em benefício da economia local e ajudando as pessoas a compreenderem a evolução de sua paisagem.

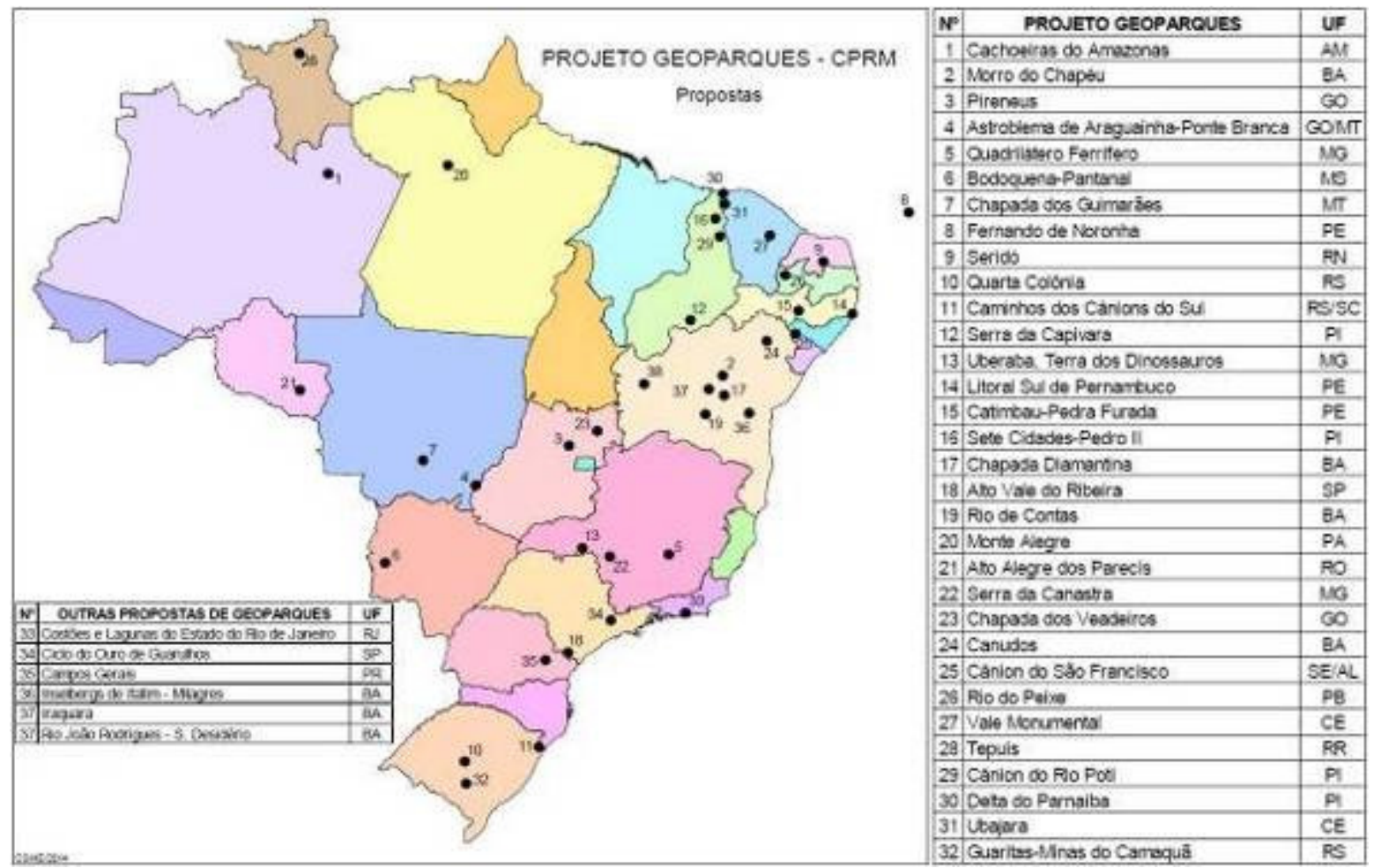

Figura 3: Mapa de localização das propostas avaliadas, em avaliação e programadas do Projeto Geoparques da CPRM. Fonte: Compilado de http://www.cprm.gov.br/.

Figure 3: Location map of the proposals evaluated in assessment and programmed the Geopark Project from CPRM. Source: Compiled from http://www.cprm.gov.br/. 
Dentro do Projeto Geoparques da CPRM diversas propostas já foram avaliadas, outras estão em fase de estudos e outras ainda serão avaliadas em trabalhos futuros. Essas propostas estão indicadas no mapa (Figura 3) e na relação apresentada na tabela 1 . O relatório técnico de algumas propostas já pode ser acessado em meio digital no link http://www.cprm.gov.br/publique/cgi/cgilua.exe/sys/start.htm?sid=134. E no final de 2012 foi também publicado o Livro "Geoparques do Brasil: propostas" (SCHOBBENHAUS; SILVA, 2012) com livre acesso em http://www.cprm.gov.br/publique/media/GEOPARQUESdoBRASIL proposta s.pdf. Nele estão descritas as primeiras 17 propostas de áreas para criação de geoparques em território brasileiro. Essas atividades foram executadas em parte por meio de parcerias com instituições federais, estaduais ou municipais ou com o apoio de universidades e instituições privadas.

Além das mencionadas propostas, deve-se, ainda, referir os seguintes aspirantes a geoparque no Brasil: Costões e Lagunas do Rio de Janeiro (Serviço Geológico do Estado do Rio de Janeiro - Diretoria de Recursos Minerais, UFRJ), Campos Gerais (Universidade Estadual de Ponta Grossa e Minérios do Paraná-Mineropar) e Ciclo do Ouro (Prefeitura de Guarulhos, São Paulo).

A iniciativa de apresentar propostas de geoparques tem tido uma excelente receptividade nos meios acadêmicos; órgãos governamentais de âmbitos federal, estadual e municipal; iniciativa privada; bem como nas populações locais. Esses aspectos levam a prever que certamente teremos em futuro próximo a implantação de novos geoparques no Brasil.

Tabela 1: Relação de propostas do Projeto Geoparques publicadas no primeiro volume do Livro Geoparques do Brasil: propostas (SCHOBBENHAUS; SILVA, 2012).

Table 1: Geoparks Project proposals relationship published the first volume of Geoparks Brazil: proposals book (SCHOBBENHAUS; SILVA, 2012).

\begin{tabular}{|l|c|l|}
\hline \multicolumn{1}{|c|}{ Geoparque (proposta) } & UF & \multicolumn{1}{|c|}{ Categoria(s) Principal(is) } \\
\hline Cachoeira do Amazonas & AM & Estratigráfico, Espeleológico, Arqueológico \\
\hline Morro do Chapéu & BA & Estratigráfico, Geomorfológico, Histórico \\
\hline Pireneus & GO & Estratigráfico, Tectônico, Geomorfológico, Histórico-Cultural \\
\hline $\begin{array}{l}\text { Astroblema Araguainha-Ponte } \\
\text { Branca }\end{array}$ & GO/MT & Astroblema (estrutura de impacto de meteorito) \\
\hline Quadrilátero Ferrífero & MG & $\begin{array}{l}\text { Estratigráfico, Paleoambiental, História da Mineração, } \\
\text { Geomorfológico, Metalogenético }\end{array}$ \\
\hline Bodoquena-Pantanal & MS & $\begin{array}{l}\text { Espeleológico, Paleoambiental, Geomorfológico, } \\
\text { Paleontológico, Metalogenético }\end{array}$ \\
\hline Chapada dos Guimarães & MT & $\begin{array}{l}\text { Geomorfológico, Paleontológico, Espeleológico, Beleza } \\
\text { Cênica }\end{array}$ \\
\hline Fernando de Noronha & PE & Ígneo, Beleza Cênica \\
\hline Seridó & RN & $\begin{array}{l}\text { Estratigráfico, Ígneo, Geomorfológico, Metalogenético, } \\
\text { Histórico-Cultural }\end{array}$ \\
\hline Quarta Colônia & RS & Paleontológico, Estratigráfico \\
\hline Caminhos dos Cânions do Sul & RS/SC & Beleza Cênica, Geomorfológico, Ígneo, Estratigráfico \\
\hline Serra da Capivara & PI & Estratigráfico, Arqueológico \\
\hline Ciclo do Ouro, Guarulhos & SP & Geomorfológico, Mineralógico, Arqueológico, Metalogenético \\
\hline $\begin{array}{l}\text { Uberaba, Terra dos } \\
\text { Dinossauros do Brasil }\end{array}$ & MG & Paleontológico \\
\hline Campos Gerais & PR & Geomorfológico, Paleontológico, Estratigráfico, Mineralógico \\
\hline Litoral Sul de Pernambuco & PE & Ígneo, Estratigráfico, Beleza Cênica, Histórico-Cultural \\
\hline $\begin{array}{l}\text { Costões e Lagunas do Estado } \\
\text { do Rio de Janeiro }\end{array}$ & RJ & $\begin{array}{l}\text { Geomorfológico, Mineralógico, Metalogenético, } \\
\text { Estratigráfico, Sedimentológico, Paleontológico, Tectônico }\end{array}$ \\
\hline
\end{tabular}




\section{O Projeto Geoparque Seridó - uma proposta em andamento}

Dentre as várias propostas de áreas já trabalhadas pelo Serviço Geológico do Brasil - CPRM uma que se destaca é o Projeto Geoparque Seridó. Principalmente por possuir um dos mais completo e importante patrimônio geológico do Nordeste, com paisagem exuberante formada por granitos, gnaisses, quartzitos e arenitos, tendo ainda a mineração que representa um grande potencial geoturístico, com destaque para o Distrito Mineiro da Brejuí, sem falar dos sítios paleontológicos e sua megafauna pleistocênica. A região possui uma riqueza cultural regional ímpar, com registros da presença homem e de animais pré-históricos, incluindo arte rupestre, além de inúmeros artesanatos em minerais e rochas.

Tendo em vista o caráter excepcional deste patrimônio geológico, associado ao aspecto cultural da região, a área proposta atende as necessidades para criação do Geoparque Seridó (NASCIMENTO; FERREIRA, 2012). Vale salientar que na região existe ainda um Pólo e Conselho de Turismo, fomentado pela Secretaria de Estado do Turismo do RN, que criaram em 2004 o Projeto Roteiro Seridó e está integrado ao Programa Territórios da Cidadania do Governo Federal. A região também já apresenta painéis interpretativos (geoturísticos) do Projeto Monumentos Geológicos do RN, criado pelo IDEMA/RN para divulgar o patrimônio geológico potiguar (Figura 4). O referido projeto conta com a sinalização de 16 monumentos geológicos, tendo na região Seridó 3 painéis já instalados (Mina Brejuí, Plúton de Acari e Pegmatito de Parelhas).
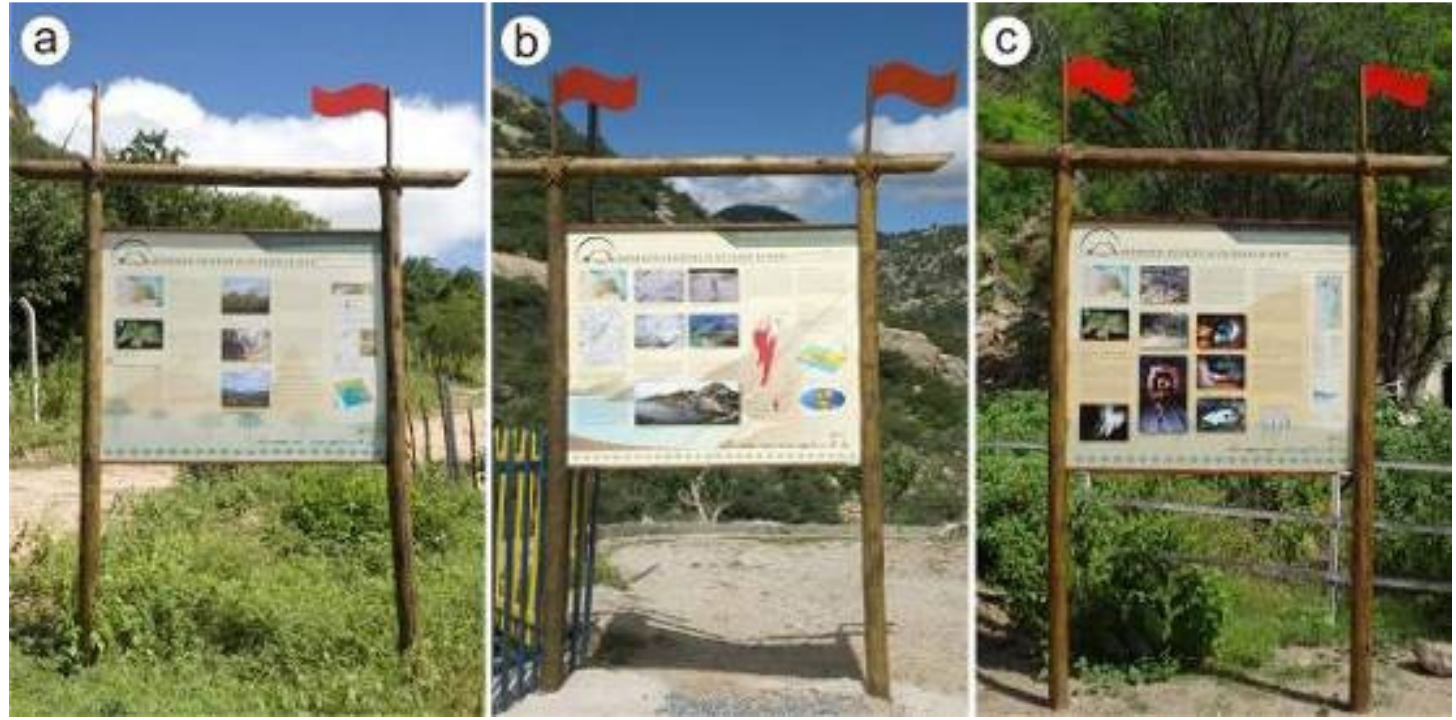

Figura 4: Sinalização geoturística associada ao Projeto Monumentos Geológicos do Rio Grande do Norte (NASCIMENTO, 2010), com destaque para as placas interpretativas dos geossítios (a) Açude Boqueirão (com os pegmatitos de Parelhas), (b) Açude Gargalheiras (com o granito de Acari) e (c) Mina Brejuí.

Figure 4: Geotourism signaling associated with the Rio Grande do Norte Geological Monuments Project (Nascimento, 2010), highlighting the interpretative boards geosites (a) Açude Boqueirão (with pegmatites Parelhas), (b) Açude Gargalheiras (with Acari granite) and (c) Brejuí Mine. 
Na região a economia foi estruturada sobre o tripé composto pela pecuária extensiva, agricultura e mineração, esta ultima baseada na exploração de minérios como scheelita, tantalita, columbita e berilo. Mais recentemente novas atividades foram introduzidas e/ou ampliadas, tais como a produção leiteira, a modernização e ampliação da caprino-ovinocultura, a atividade ceramista e o desenvolvimento do setor terciário, com destaque para o comercio e a diversificação de serviços (principalmente o turismo). A população estimada para os 14 municípios em 2009 é de 217.419 habitantes, tendo Caicó e Currais Novos o maior contingente populacional (63.006 e 43.536 habitantes, respectivamente). $O$ Índice de Desenvolvimento Humano (IDH) tem média de 0,640 , tendo Caicó o maior valor $(0,756)$ e Cerro Corá o menor $(0,592)$.

O portão de entrada do geoparque, para quem vem de Natal (capital do estado), pode ser considerado a cidade de Currais Novos que está a 172 $\mathrm{km}$ da capital potiguar. Caicó é dentre as cidades da região do Seridó, a mais afastada da capital, distando $256 \mathrm{~km}$. Já a distância entre os municípios situados em pontos extremos do referido geoparque não ultrapassa os $100 \mathrm{~km}$, como é o caso de Cerro Corá (extremo norte da área) até Parelhas (extremo sul).

A soma das áreas que envolvem os 14 municípios (Bodó, Cerro Corá, Lagoa Nova, Currais Novos, São Vicente, Tenente Laurentino Cruz, Florânia, Caicó, São José do Seridó, Cruzeta, Acari, Carnaúba dos Dantas, Jardim do Seridó e Parelhas). da proposta Geoparque Seridó totaliza 5.900 $\mathrm{km}^{2}$ e o mesmo possui 25 sítios geológicos inventariados (Tabela 2). Porém 3 municípios não possuem geossítios cadastrados, mas são territórios situados entre municípios com geossítios trabalhados.

Tabela 2: Relação dos 25 geossítios inventariados junto ao Projeto Geoparque Seridó.

Table 2: List of 25 geosites inventoried by the Geopark Seridó Project.

\begin{tabular}{l|l|l|l}
\hline № & Geossítios & Municípios & Descrição Sumária \\
\hline 01 & Serra Verde & Cerro Corá & Geoformas em granito e arte rupestre \\
\hline 02 & Cruzeiro de Cerro Corá & Cerro Corá & Dique de granito \\
\hline 03 & Vale Vulcânico & Cerro Corá & Derrame basáltico e disjunções colunares \\
\hline 05 & Mirante Santa Rita & Lagoa Nova & Superfície de aplanamento e mirante \\
\hline 06 & Morro do Totoró & $\begin{array}{l}\text { Currais } \\
\text { Novos }\end{array}$ & Geoformas em granito e arte rupestre \\
\hline 07 & Mina Brejuí & $\begin{array}{l}\text { Currais } \\
\text { Novos }\end{array}$ & Dique de pegmatito e textura gráfica \\
\hline 08 & Cânion dos Apertados & $\begin{array}{l}\text { Currais } \\
\text { Novos } \\
\text { Novos }\end{array}$ & $\begin{array}{l}\text { Galerias subterrâneas ério de } \\
\text { scheelita }\end{array}$ \\
\hline 09 & Dique Ceará-Mirim & São Vicente & Cânions em quartzitos e fraturas \\
\hline 10 & $\begin{array}{l}\text { Contato Jucurutu } \\
\text { Seridó }\end{array}$ & São Vicente & Contato paragnaisse e micaxisto \\
\hline 11 & Monte das Graças & Florânia & $\begin{array}{l}\text { Ortognaisses do Complexo Caicó } \\
\text { mirante }\end{array}$ \\
\hline 12 & Serra da Garganta & Florânia & Granito em relevo e mirante \\
\hline 13 & Gruta da Caridade & Caicó & Caverna com estalactites e arte rupestre \\
\hline 14 & Ortognaisse Caicó & Caicó & Ortognaisses em afloramento clássico \\
\hline & \multicolumn{2}{|l}{ Continua... }
\end{tabular}


...Continuação.

\begin{tabular}{|c|c|c|c|}
\hline № & Geossítios & Municípios & Descrição Sumária \\
\hline 15 & Açude de Cruzeta & Cruzeta & $\begin{array}{l}\text { Micaxistos de baixo grau metamórfico } \\
\text { (filitos) }\end{array}$ \\
\hline 16 & $\begin{array}{ll}\text { Estaurolitas } & \text { Fazenda } \\
\text { Gregório } & \\
\end{array}$ & Cruzeta & $\begin{array}{l}\text { Micaxistos de alto grau metamórfico e } \\
\text { gemas }\end{array}$ \\
\hline 17 & Açude Gargalheiras & Acari & Serras de granito e mirante \\
\hline 18 & Cruzeiro de Acari & Acari & $\begin{array}{l}\text { Granito porfirítico em afloramento } \\
\text { clássico }\end{array}$ \\
\hline 19 & Poço do Arroz & Acari & Arte rupestre em granito e pegmatito \\
\hline 20 & $\begin{array}{ll}\text { Marmitas do Rio } \\
\text { Carnaúba }\end{array}$ & Acari & $\begin{array}{l}\text { Marmitas e caldeirões em granito e } \\
\text { arte rupestre }\end{array}$ \\
\hline 21 & Monte do Galo & $\begin{array}{l}\text { Carnaúba dos } \\
\text { Dantas }\end{array}$ & Dique de pegmatito e mirante \\
\hline 22 & Xiquexique & $\begin{array}{l}\text { Carnaúba dos } \\
\text { Dantas }\end{array}$ & Serra de quartzito e arte rupestre \\
\hline 23 & Ponte da Pedra Lavrada & Jardim do Seridó & Granito cortado por pegmatito \\
\hline 24 & Açude Boqueirão & Parelhas & $\begin{array}{l}\text { Metaconglomerados, quartzitos } \\
\text { mirante }\end{array}$ \\
\hline 25 & Mirador & Parelhas & Arte rupestre em metaconglomerado \\
\hline
\end{tabular}

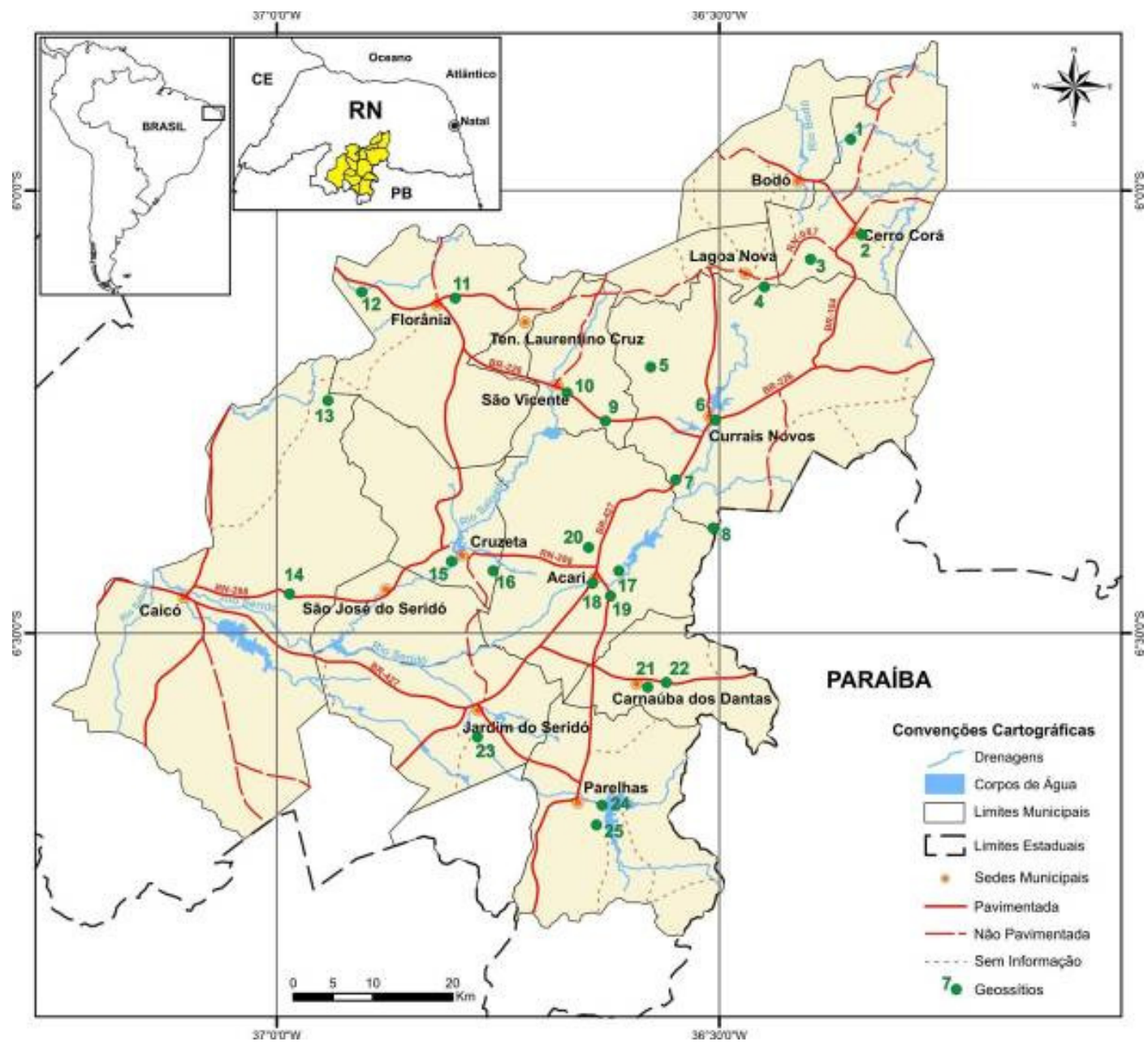

Figura 5: Localização da área referente a proposta Geoparque Seridó, no Estado do Rio Grande do Norte. Fonte: Compilado de Nascimento e Ferreira (2012).

Figure 5: Location of the area the Seridó Geopark proposed in the state of Rio Grande do Norte. Source: Compiled from Nascimento e Ferreira (2012). 
$\mathrm{Na}$ região da proposta Geoparque Seridó ocorre um dos mais completo e belo patrimônio geológico encontrado no Nordeste, os quais são decorrentes dos inúmeros processos naturais a que esta região foi submetida ao longo do Tempo Geológico (Figura 6).
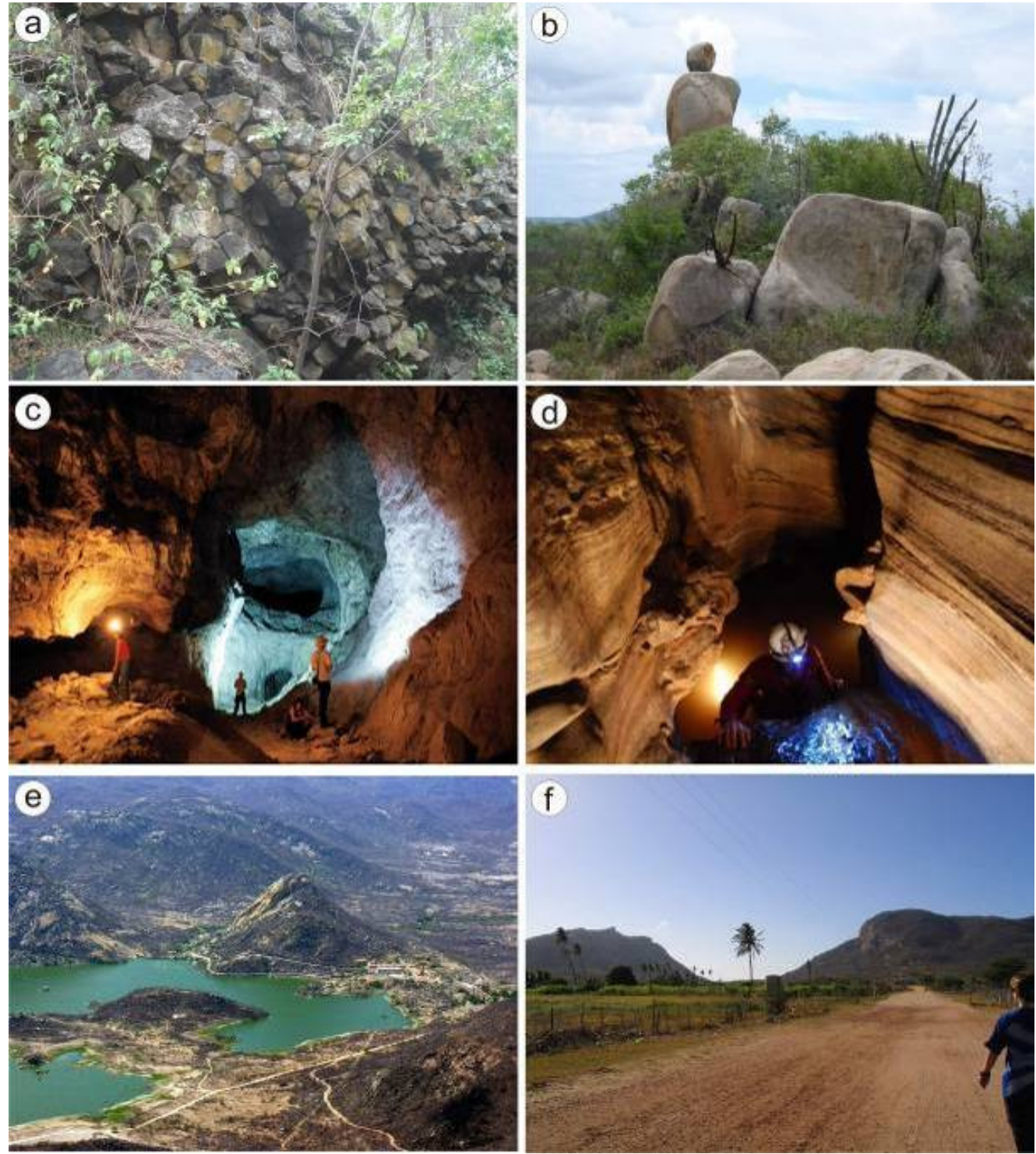

Figura 6: Diferentes exemplos do patrimônio geológico encontrado em geossítios do Projeto Geoparque Seridó. (a) Disjunções colunares em basaltos do Geossítio Vale Vulcânico, em Cerro Corá; (b) Geoforma conhecida como Pedra do Caju no Geossítio Pico do Totoró, em Currais Novos; (c) Um dos salões visitados dentro do Geossítio Mina Brejuí, em Currais Novos; (d) Visão interna de parte da gruta no Geossítio Gruta da Caridade, em Caicó; (e) Vista aérea de parte do Geossítio Açude Gargalheiras, em Acari; e (f) Visão geral da parte norte da Serra das Queimadas com destaque para o boqueirão no Geossítio Açude Boqueirão, em Parelhas.

Figure 6: Different examples of geological heritage found in geosites of Seridó Geopark Project. (a) Disjunctions columnar basalts in the Vale Vulcâncio Geosite, in Cerro Cora; (b) Geoform known as Pedra do Caju on Pico Totoró Geosite, in Currais Novos; (c) One of the popular halls within the Brejuí Mine Geosite, in Currais Novos; (d) Inside view of part of the cave in Gruta da Caridade Geosite, in Caicó; (e) Aerial view of part of Açude Gargalheiras Geosite, in Acari; and (f) Overview of the northern part of the Queimadas ridge especially in Açude Boqueirão Geosite, in Parelhas. 
O relevo se destaca na paisagem proporcionando cenários exuberantes que permitem a contemplação de novas áreas. $\mathrm{Na}$ constituição do relevo, destacam-se serras, picos e afloramentos de rochas, cujos melhores exemplos são: Serra de Santana, Casa de Pedra e Muralha Vulcânica em Cerro Corá; serras do Chapéu, de Acauã, Cânions dos Apertados, Pico do Totoró, em Currais Novos; serras do Bico da Arara, do Pai Pedro, da Rajada, Marmitas do Rio Carnaubinha e Açude Gargalheiras, em Acari; Serra do Xiquexique e Monte do Galo, em Carnaúba dos Dantas; serras das Queimadas e da Coruja, em Parelhas; e as serras de São Bernardo, da Formiga e a Gruta da Caridade, em Caicó. Estes relevos são formados por granitos, gnaisses, quartzitos e arenitos.

A mineração representa um grande potencial geoturístico para a região, destacando-se o Distrito Mineiro da Brejuí, em Currais Novos. Na Mina Brejuí, onde se explora a scheelita desde a década de 40, existem cerca de $60 \mathrm{~km}$ de túneis subterrâneos, onde 300 metros destes já são utilizados para visitação. Há também um museu/memorial instalado nas dependências da mina, onde é revelada toda a sua história. Em Parelhas, encontra-se uma enorme diversidade de minerais com destaque para a turmalina, água marinha, granada e ametista, que atraem turistas e comerciantes.

Observam-se registros do homem e de animais pré-históricos, nos inúmeros sítios arqueológicos/paleontológicos da região, destacando a arte rupestre em Carnaúba dos Dantas, com mais de 90 sítios catalogados (dentre eles sítios Xiquexique I e II, Casa Santa e Pedra do Alexandre), com gravuras e pinturas das tradições Nordeste, Agreste e Itaquatiaras; em Parelhas está localizado o Sítio Mirador, onde foram encontrados vestígios da presença do homem antigo, com datações de 10.000 AP (NASCIMENTO; SANTOS, 2013); em Cerro Corá há o Sítio de Serra Verde; além de outros espalhados pelos municípios de Acari, Currais Novos e Jardim do Seridó.

Convém lembrar, que os geossítios mencionados são apenas uma pequena amostra do que a região do Seridó possui de patrimônios geológico e cultural. Diante desse panorama, ressalta-se a importância de um planejamento prévio e estratégico para o desenvolvimento de ações que visem caracterizar esses geossítios, como por exemplo, um inventário. Partindo da premissa de que só é possível conservar algo se houver um conhecimento prévio, este inventário e todo o conjunto de atividades voltado à geoconservação da região do Seridó Potiguar irão possibilitar a criação (futura) do Geoparque Seridó.

Importante ressaltar que as atividades realizadas junto a proposta Geoparque Seridó deram início em 19 de abril de 2010, por meio da parceria entre a CPRM e a UFRN, a qual possibilitou nesses 5 anos a realização de diferentes ações com destaque para:

(a)Inventário de 25 geossítios na região do Seridó Potiguar, nos municípios de Cerro Corá, Lagoa Nova, Currais Novos, São Vicente, Florânia, Caicó, Cruzeta, Acari, Carnaúba dos Dantas, Jardim do Seridó e Parelhas (Figura 4). Esta proposta contempla uma área que inclui ainda Bodó, Tenente Laurentino Cruz e São José do Seridó, 
perfazendo cerca de $6000 \mathrm{~km}^{2}$. Os resultados estão divulgados no site da CPRM por meio do link http://www.cprm.gov.br/geoecoturismo/geoparques/serido/index.html e no Livro "Geoparques do Brasil: propostas" (capítulo 11), lançando em 2012, com acesso em http://www.cprm.gov.br/publique/media/GEOPARQUESdoBRASIL_propos tas.pdf;

(b) Projetos na UFRN: (i) Estudo Técnico e Diagnóstico para Criação do Geoparque Seridó, Estado do RN (de pesquisa, em 2010); (ii) Patrimônio Geológico da Região do Seridó (RN, NE do Brasil): inventariação e integração de geossítios para embasar proposta de criação de Geoparque (de ação acadêmica associada, em 2012); (iii) Educação Patrimonial em Meio Natural em municípios do Geoparque Seridó (Região Seridó, RN); (iv) Roteiros do Seridó: análise do potencial turístico do Seridó Potiguar e (v) Elaboração do Plano de Desenvolvimento do Turismo do Município de Currais Novos (de ações acadêmicas associadas, em 2013) e;

(c)Elaboração de Dissertação: Geoparque Seridó, RN: valores turísticos e gestão (defendida em 2013 no PPGTUR/UFRN e agraciada com o prêmio de melhor dissertação de turismo de 2013 pela ANPTUR). No momento está sendo produzida a dissertação "Prática Turística em Geossítios: uma avaliação ambiental no Projeto Geoparque Seridó", a ser defendida em 2015.

Nesse período novas parcerias vieram somar esforços na construção da proposta Geoparque Seridó, com destaque para o SEBRAE/RN e o IPHAN/RN. Além de inúmeros projetos voltados diretamente para o turismo da região em lide, o SEBRAE/RN publicou o Guia Turístico da Região Seridó contemplando informações sobre diversos geossítios trabalhados. $O$ IPHAN/RN tem garantido a preservação do patrimônio arqueológico em geossítios dos municípios de Carnaúba dos Dantas e Parelhas, seja pela atuação para o fiel cumprimento da legislação, seja pela execução de obras de socialização (com acessibilidade) que garantem a visitação controlada aos geossítios que contêm arte rupestre desenhada nas rochas desses geossítios (Xiquexique e Mirador). Além disso, publicou o livro "Geodiversidade na Arte Rupestre no Seridó Potiguar" contemplando a descrição de diferentes elementos da geodiversidade em geossítios da proposta Geoparque Seridó (NASCIMENTO; SANTOS, 2013).

No momento novas ações estão sendo criadas junto a proposta Geoparque Seridó, para serem realizadas em 2015-2016, são elas:

(a)Cadastros de novos geossítios (inventário e quantificação);

(b)Promoção de cursos de educação ambiental e capacitação de guias de turismo, condutores e gestores; 
(c)Elaboração de monografias de graduação (Curso de Turismo/CERES/UFRN), dissertações de mestrado e tese de doutorado (PPGTUR/UFRN);

(d)Realização de projeto de extensão para definição de trilhas geoturísticas; $\mathrm{e}$

(e)Preparação de material promocional (folder e vídeo) sobre o Projeto Geoparque Seridó, permitindo assim levar conhecimento sobre conservação, educação e turismo às comunidades envolvidas com a região em lide.

\section{Considerações Finais}

Por meio do conteúdo apresentado, pode-se perceber a relevância da temática, bem como de sua efetivação enquanto práxis para 0 desenvolvimento regional, não somente da região do Seridó do RN, mas para tantos quantos queiram se apropriar desta estratégia.

A criação de uma rede global de geoparques permitiu a difusão e divulgação desses lugares que são vistos pela UNESCO como importantes para o desenvolvimento do turismo. E é por meio dessa atividade que é possível articular eixos primordiais como educação, proteção e desenvolvimento sustentável, que associado a perspectiva econômica que os geoparques podem gerar, em razão da série de atividades que podem ser desenvolvidas em seu espaço, condicionam a um importante instrumento de desenvolvimento regional.

Por essa razão o geoparque é considerado importante quando se lista a série de benefícios que esses espaços podem gerar como atividades turísticas, culturais, científicas e educacionais, a continuidade e incremento da economia por meio de novos produtos associado ao estimulo de participação popular e sua inserção no âmbito de um geoparque.

A representatividade desses territórios a nível mundial possibilitou que os países focassem essa perspectiva para sua realidade, assim aqui no Brasil a CPRM lançou o Projeto Geoparque Brasil com o intuito de identificar possíveis áreas potenciais para a criação de geoparque. Dentre as propostas apresentadas pela CPRM encontra-se o Projeto Geoparque Seridó, região que contempla áreas de singular valor do patrimônio geológico do Seridó potiguar.

O contexto potiguar apresenta singularidades e expressa subsídios suficientes para a criação do Geoparque Seridó. A parceria UFRN e CPRM possibilitou a concretização do geoparque em uma proposta, além das ações desenvolvidas na academia que sustentam ainda mais a relevância da efetiva implantação do geoparque. Associado a essas premissas, a região que contempla a área do referido geoparque possui medidas relacionadas ao turismo (polo e o conselho de turismo) e parcerias com SEBRAE e IPHAN que desenvolveram articulações em prol do Geoparque Seridó. 
Por esse conjunto de ações associada com as singularidades do local, patrimônio geológico ímpar com presença de artes rupestres, aspectos históricos, culturais, científicos e religiosos, o geoparque Seridó tem importante relevância no contexto de desenvolvimento regional por permitir a disseminação do turismo para municípios que contemplam o geoparque, sendo uma forma de descentralizar o turismo na capital do estado, além de permitir uma educação ambiental aos moradores e visitantes do local.

Vale salientar que o geoparque é uma oportunidade econômica as regiões que o integram, possibilitando às comunidades meios de formar, criar e inovar produtos que estejam relacionados ao contexto do geoparque e assim, assegurar a geração de emprego, renda com suporte no desenvolvimento local desse espaço. A articulação acadêmica vem contribuir na perspectiva de subsidiar ferramentas que auxiliem a gestão deste espaço, bem como formas de sensibilizar a comunidade para relevância do local, o que se traduz no contexto da pesquisa, possibilitando uma aproximação da academia e sua real contribuição além universidade, aplicabilidade prática das pesquisas voltadas para o geoparque Seridó.

\section{Referências Bibliográficas}

BRITO, L.S.M.; PERINOTTO, A.R.C. Difusão da Ciência no Geopark Araripe, Ceará, Brasil. Anuário do Instituto de Geociências, v.35(1), p. 4248, 2012.

EDER, F.W.; PATZAK, M. Geoparks - geological attractions: a tool for public education, recreation and sustainable economic development. Episodes, v.27, p. 162-164, 2004.

MARTINI, G. Geoparks ... a vision for the future. Geologia USP publicação especial, v.5, p. 85-90, 2009.

MC KEEVER, P.J.; ZOUROS, N. Geoparks: celebrating Earth heritage, sustaining local communities. Episodes, v.28(4), p. 274-278, 2005.

MOREIRA, J.C. Geoturismo e Interpretação Ambiental. Ponta Grossa: Editora UEPG, 2011. 157p.

NASCIMENTO, M.A.L. Patrimônio Geológico e Geoturismo. In: PFALTZGRAFF, P.A.S.; TORRES, F.S.M. (org.). Geodiversidade do Estado do Rio Grande do Norte. Rio de Janeiro: CPRM - Serviço Geológico do Brasil, p. 133-144, 2010.

NASCIMENTO, M.A.L.; FERREIRA, R.V. Seridó (RN). In: SCHOBBENHAUS, C.; SILVA, C.R. (org). Geoparques do Brasil: propostas. Rio de Janeiro: CPRM - Serviço Geológico do Brasil, p. 361416, 2012.

NASCIMENTO, M.A.L.; SANTOS, O.J. Geodiversidade na Arte Rupestre no Seridó Potiguar. Natal: Instituto do Patrimônio Histórico e Artístico Nacional, 2013. 62p. 
NASCIMENTO, M.A.L.; RUCHKYS, Ú.A.; MANTESSO NETO, V. Geodiversidade, Geoconservação e Geoturismo: trinômio importante para proteção do patrimônio geológico. São Paulo: Sociedade Brasileira de Geologia, 2008. 82p.

SCHOBBENHAUS, C.; SILVA, C.R. Geoparques do Brasil: propostas. Rio de Janeiro: CPRM - Serviço Geológico do Brasil, 2012. 745p.

URQUÍ, L.C. Geoconservación. Catarata: Instituto Geológico y Minero de España, 2012. 126p.

ZOUROS, N. The European Geoparks Network. Episodes, v.27(3), p. 165$171,2004$.

Marcos Antonio Leite do Nascimento: Universidade Federal do Rio Grande do Norte, Natal, RN, Brasil.

E-mail: caxexa@yahoo.com.br.

Link para o currículo Lattes: http://lattes.cnpq.br/5356037408083015

Cristiane Soares Cardoso Dantas Gomes: Universidade Federal do Rio Grande do Norte, Natal, RN, Brasil.

E-mail: crisscdantas@gmail.com.

Link para o currículo Lattes: http://lattes.cnpq.br/8040585386178528

Artemísia dos Santos Soares de Brito: Universidade Federal do Rio Grande do Norte, Natal, RN, Brasil.

E-mail: artemisiasoares@yahoo.com.br.

Link para o Lattes: http://lattes.cnpq.br/1052024626478722

Data de submissão: 08 de abril de 2015

Data de recebimento de correções: 03 de maio de 2015

Data do aceite: 03 de maio de 2015

Avaliado anonimamente 